\title{
Salivary Alpha-Amylase Activity in Relation to Cardiometabolic Status in Japanese Adults without History of Cardiovascular Disease
}

\author{
Ai Ikeda ${ }^{1,2}$, Andrew Steptoe ${ }^{2}$, Eric J Brunner ${ }^{2}$, Koutatsu Maruyama ${ }^{3}$, Kiyohide Tomooka ${ }^{1}$, Tadahiro Kato ${ }^{4}$, \\ Noriko Miyoshi ${ }^{1}$, Shinji Nishioka ${ }^{3,5}$, Isao Saito ${ }^{6}$ and Takeshi Tanigawa ${ }^{1}$
}

\begin{abstract}
${ }^{1}$ Department of Public Health, Juntendo University Graduate School of Medicine, Tokyo, Japan
${ }^{2}$ Department of Epidemiology and Public Health, Faculty of Population Health Sciences, University College London, London, UK

${ }^{3}$ Laboratory of Community Health and Nutrition, Special Course of Food and Health Science, Department of Bioscience, Graduate School of Agriculture, Ehime University, Matsuyama, Japan

${ }^{4}$ Center for Education and Educational Research, Faculty of Education, Ehime University, Matsuyama, Japan

${ }^{5}$ Ehime Dental Association, Ehime, Japan

${ }^{6}$ Department of Public Health and Epidemiology, Faculty of Medicine, Oita University, Yufu, Japan
\end{abstract}

Aims: Stress is known to be a potential contributor to the development of diabetes and hypertension. However, the biological mechanisms underlying the association between cardiometabolic risk markers and the biological stress response have not yet been determined. Therefore, we examined salivary alpha-amylase and heart rate variability in relation to cardiometabolic status in a sample of healthy Japanese men and women.

Methods: Participants (473 men and 1,029 women aged 30-84) underwent a $75 \mathrm{~g}$ oral glucose tolerance test after a 10-hr fast. The homeostasis model assessment index for insulin resistance was based on fasting and 2-hr postload glucose and insulin concentrations. Sitting blood pressure was measured twice after rest. A saliva sample was collected in the morning and salivary alpha-amylase was assayed. A 5-min heart rate variability recording was evaluated using time-domain indices of standard deviations of normal-to-normal intervals and root mean square of successive differences. Multivariate linear regression models were used to estimate associations between salivary alpha-amylase and each outcome measure.

Results: Salivary alpha-amylase was associated with fasting glucose $(\beta=0.008 ; 95 \% \mathrm{CI}=0.002,0.014), 2$-hr postload glucose $(\beta=0.023 ; 95 \% \mathrm{CI}=0.004,0.041)$, homeostasis model assessment index for insulin resistance $(\beta=0.032 ; 95 \% \mathrm{CI}=0.000,0.064)$, systolic $(\beta=1.603 ; 95 \% \mathrm{CI}=0.479,2.726)$ and diastolic $(\beta=0.906 ; 95 \%$ $\mathrm{CI}=0.212,1.600)$ blood pressures among women. These associations remained significant after further adjustment for heart rate variability measures.

Conclusions: The elevation of salivary alpha-amylase may reflect a dysfunction of the sympathetic nervous system associated with cardiometabolic abnormalities in women.

Key words: Salivary alpha-amylase activity, Glucose intolerance, Insulin resistance, Blood pressure

\section{Introduction}

The prevalence of type 2 diabetes is increasing rapidly worldwide, and fasting plasma glucose levels have risen globally since $1980^{1}$. Even in Japan, where body mass index (BMI) is typically low, the prevalence of type 2 diabetes and the population attributable fraction for cardiovascular disease have increased markedly ${ }^{2)}$. Stress is a potential contributor to chronic hyperglycemia in diabetes ${ }^{3,4)}$. Previous epidemiological studies have confirmed the association of stress with a higher risk of developing type 2 diabetes melli-

Address for correspondence: Takeshi Tanigawa, Department of Public Health, Juntendo University Graduate School of Medicine, 2-1-1 Hongo, Bunkyo-ku, Tokyo 113-8421, Japan. E-mail: tataniga@juntendo.ac.jp

Received: October 29, 2019 Accepted for publication: August 31, 2020 
tus ${ }^{5-8)}$. In an effort to understand the biological mechanisms underlying this, a recent study has investigated the association between diabetes and biological stress response measured by salivary alpha amylase $(\mathrm{sAA})^{9)}$.

Psychological stress leads to an increase in activation of the autonomic nervous system through a combination of sympathetic and parasympathetic innervation of the salivary glands, leading to the release of $\mathrm{sAA}^{10,11)}$. A substantial literature reveals that $\mathrm{sAA}$ is a correlate of sympathetic nervous activity ${ }^{12)}$ under conditions of stress ${ }^{11,13,14)}$. Moreover, sAA was negatively associated with root mean square of successive differences in the normal-to-normal (RR) intervals (RMSSD), suggesting a shift in autonomic balance in favour of sympathetic activation in stressful conditions $^{14)}$.

The literature assessing sAA in relation to cardiometabolic status is limited. A small case-control study with 125 diabetes cases and 125 controls found no significant association between sAA and diabetes ${ }^{9)}$. No previous studies have tested the association between sAA and fasting glucose and insulin resistance in a healthy population. Moreover, there was only a small experimental study that found a correlation between psychological stress induced changes in sAA and systolic blood pressure (SBP) ${ }^{15}$. The aim of our study was therefore to examine the association between cardiometabolic risk markers and sAA in a large sample of Japanese men and women.

In contrast, lower heart rate variability (HRV) has been associated with increased risk of diabetes ${ }^{16)}$, insulin resistance ${ }^{17)}$ and hypertension ${ }^{18)}$. A recent study from our group has also suggested that HRV, as indexed by the standard deviation of the RR intervals (SDNN) and RMSSD, is inversely associated with higher fasting glucose as well as blood pressure ${ }^{19)}$. However, no previous study has examined autonomic nervous dysfunction classified by the combination of sympathetic and parasympathetic biomarkers in relation to glucose, insulin resistance, and blood pressure.

\section{Aim}

To facilitate a more detailed examination of the role of autonomic nervous function, we examined sAA and HRV in relation to blood pressure level, and glucose and insulin levels assessed during oral glucose tolerance tests (OGTT). We hypothesized that elevated sAA would be associated with higher levels of glucose and insulin as well as elevated blood pressure. We also conjectured that the associations might be modified by HRV. Data are from the Toon Health Study (THS), an ongoing cohort of healthy communitydwelling men and women.

\section{Methods}

Study Population

The THS has been described in detail elsewhere ${ }^{20)}$. In brief, the THS is a longitudinal study established in 2009-2013 to investigate new risk factors for diabetes and cardiovascular disease and involves 2,032 community-dwelling men and women from Toon City, Ehime Prefecture, Japan who were aged 30-79 years at the time of entry. Toon City is in a rural area located in the southern part of Japan with a population of $-22,000$. Participants were voluntarily recruited by newspaper advertisements, posters, or invitations. Participants have been asked to return for onsite physical examinations and questionnaires every 5 years. A total of 1,777 individuals $(n=1,396$ enrolled since 2009; $n=381$ newly enrolled) participated in the 5-year follow-up study between 2014 2017; therefore, our study population was slightly different form the original THS population. Individuals who did not have sAA measured $(n=19)$ or an oral glucose tolerance test (OGTT) performed $(n=98)$, were previously diagnosed with coronary heart disease or stroke $(n=143)$, or had atrial fibrillation on an ECG at the time of sAA measurement $(n=15)$ were excluded from the present study. The OGTT was not performed if an individual had a prior history of gastrectomy to avoid the occurrence of dumping syndrome after the glucose load $(n=15)$, or if his/her fasting blood glucose level measured by a portable glucose monitor was $\geq 7.8 \mathrm{mmol} / \mathrm{L}$, high enough to be diagnosed as diabetes $(n=18)$ or was on medication for diabetes $(n=65)$. Finally, 1,502 (473 men and 1,029 women) individuals aged between 30 and 84 were included in the analysis. The study protocol was approved by ethics committees of Juntendo University and Ehime University.

\section{Measurements}

Collection of chewing-gum-stimulated saliva and Assay for salivary alpha-amylase

All participants were required to fast for at least $10 \mathrm{~h}$ before the study health examination. Saliva was collected for each participant in the morning after stimulation by chewing gum. The participants chewed $1 \mathrm{~g}$ of bland and flavorless Salivar Gum (Tokyo Shizaisha, Tokyo, Japan) for $5 \mathrm{~min}$. While they were chewing, their saliva was collected into plastic tubes. Collected saliva was weighed, and the salivary flow rate was calculated in $\mathrm{g} / \mathrm{min}$. The saliva collecting tubes were centrifuged at 3,000 rpm for $15 \mathrm{~min}$ at $4{ }^{\circ} \mathrm{C}$, and saliva samples were then stored at $-80^{\circ} \mathrm{C}$ until they were assayed. All samples were tested in the same series to avoid any variations between tests. A kinetic 
reaction assay kit (Salimetrics, LLC, MA, USA) was used for sAA measurements. A plate reader (Vmax PowerWave XS, Bio-Tech Instruments, Tokyo, Japan) was used for salivary determination by $405 \mathrm{~nm}$ filters for sAA. The intra-assay coefficient of variation and inter-assay reproducibility for sAA were $5.47 \pm 1.49$ and $4.7 \pm 0.15 \%$, respectively.

\section{Assessment of Autonomic Function}

Analysis of HRV was used as a non-invasive tool to assess cardiac autonomic control (TAS9; YKC Co. Ltd, Tokyo, Japan). Pulse rate was recorded for $5 \mathrm{~min}$ using a fingertip pulse wave sensor, and the following time-domain measures of HRV were then determined: SDNN and RMSSD. The power spectrum was decomposed into its frequency components and quantified in terms of the relative intensity (power) of each component. The power spectrum was divided into frequency bands, and we determined the high frequency band (HF) $(0.15-0.40 \mathrm{~Hz})$ and the low frequency band (LF) $(0.04-0.15 \mathrm{~Hz})$. The HF and LF power and the LF/HF ratio were used for the analysis.

We previously performed 24-hr Holter ECG monitoring (PMP400; Pacific Medico, Co., Ltd., Tokyo, Japan) in a subsample of study participants ${ }^{21)}$. To validate the 5-min HRV measurements using the fingertip device, a power spectral analysis of RR intervals from the ECG was performed every five minutes over a 24 -hr period. For each 5-min interval, we calculated LF, HF, and the LF/HF ratio in the same frequency bands. The validation study suggested that the 5-min HRV parameters (i.e., heart rate, LF, HF, and $\mathrm{LF} / \mathrm{HF}$ ) measured from fingertip pulse recordings were moderately associated with the HRV parameters from 24-hr Holter ECG recordings ( $\mathrm{r}=0.53$ for LF; $r=0.59$ for $\mathrm{HF}$; $r=0.53$ for $\mathrm{LF} / \mathrm{HF}$ ).

\section{Blood Measures}

Overnight fasting blood samples were drawn from the antecubital vein into vacuum tubes containing a serum separator gel. The serum tube was centrifuged immediately at $3000 \times \mathrm{g}$ for $15 \mathrm{~min}$, and the separated serum was sent to the laboratory for analysis.

All participants underwent OGTT after at least a $10 \mathrm{hr}$ fast, and 2-hr postload glucose and insulin concentrations were measured by standard laboratory methods. Serum glucose was measured by the hexokinase method (Sysmex, Kobe, Japan) using an automatic analyzer (7600-D; Hitachi Co., Tokyo, Japan). Insulin was measured using the electrochemiluminescence method with ECLusys (Roche Diagnostics, Tokyo, Japan).

The homeostasis model assessment index for insulin resistance (HOMA-IR) was calculated as fasting serum insulin $(\mathrm{FSI})(\mu \mathrm{U} / \mathrm{mL}) \times$ fasting serum glucose (FSG) $(\mathrm{mg} / \mathrm{dL}) / 405^{22}$.

Blood pressure was measured twice in the sitting position after a rest of at least 5 min using an automatic sphygmomanometer (BP-103ilI; OMRON Colin Co., Tokyo, Japan). The mean of two measurements was used for analysis.

\section{Covariates}

A self-administrated questionnaire was used to assess medical history (presence of hypertension, dyslipidemia, or diabetes), smoking habits, alcohol consumption, menopausal status, educational attainment level, marital status, employment status, and depressive symptoms. The amount of alcohol consumed each week was evaluated by measuring the weekly frequency of drinking and the type of alcoholic beverage consumed (beer, sake, whiskey, shochu, or wine). A regular alcohol drinker was defined as an individual with alcohol consumption greater than or equal to 1 g/week. Physical activity levels were assessed using a validated questionnaire, which consisted of 14 questions on occupation, locomotion, housework, sleep time, and leisure time physical activities ${ }^{23)}$. Responses for each physical activity category were converted to metabolic equivalents (METs), according to the Compendium by Ainsworth et al. (2000) and expressed as METs.h/day. BMI was calculated as weight divided by height squared. Overweight status was defined as having a BMI greater than or equal to $25 \mathrm{~kg} / \mathrm{m}^{224}$. Depressive symptoms were assessed with two selfreport questions that measured core aspects of depression: "Have you felt uninterested in doing things or been unable to enjoy anything in the past month?" and "Have you been feeling depressed or hopeless for the past month?" Participants who responded "yes" to either of these two questions were considered to have significant depressive symptoms. Another factor that may be relevant is periodontal disease. Probing depth (PD), a measure of the depth of periodontal pockets, was collected along with sAA in a subsample of the study population $(n=783)$ in 2014-2015. PD was measured at six sites per tooth using an automated probe with a constant force $(20 \mathrm{~g})$ on all teeth present in the mouth, excluding the third molars. PD $\geq 4 \mathrm{~mm}$ was considered an indicator of chronic periodontitis $^{25)}$.

\section{Statistical Analysis}

We analyzed the concentration of sAA divided by the volume of saliva collected during the timed sampling period. The values of glucose, HOMA-IR, sAA, SDNN, RMSSD, and LF/HF ratio were natural log- 
transformed in order to improve the normality of the data distribution. Analysis of variance (ANOVA) was used to compare mean values and the chi-square test to compare proportions in the descriptive analyses of men and women. ANOVA was also used to compare mean values of sAA by each covariate. Sex-specific multivariate linear regression models were used to estimate associations between sAA and each outcome measure including fasting glucose, 2 -hr postload glucose, HOMA-IR, SBP, and diastolic blood pressure (DBP), and adjusting for age (years), education attainment level $(<$ college education or greater than or equal to college education), employment status (unemployed, full-time, part-time, or self-employed), BMI $\left(\mathrm{kg} / \mathrm{m}^{2}\right)$, menopause (yes/no), use of antihypertensive agents (yes/no), physical activity (metabolic equivalents, METs, in quartiles), smoking (nonsmoker or current smoker), and alcohol consumption status (non-drinker or current drinker). To check for effect modification in the sAA analyses, we also stratified analyses according to SDNN (using the median cut points of 3.63 for men and 3.55 for women), RMSSD (using the median cut points of 3.22 for men and 3.26 for women), LF/HF ratio (using the median cut points of 1.14 for men and 1.04 for women). We checked for statistical interactions by using crossproduct terms of sAA and stratifying variables along with the main effects. Statistical significance was assumed at $P<0.05$. All statistical analyses were performed using SAS software, version 9.4 (SAS Institute, Inc., Cary, NC, USA).

\section{Results}

The characteristics of the study sample are presented in Table 1. Men were likely to be older, married, highly educated, and have full-time employment compared with women. The levels of smoking, drinking and obesity were also higher in men than women. The means of glucose, HOMA-IR, and both systolic and diastolic blood pressures were higher in men than women. The mean of sAA was lower in men than women.

The sex-specific mean differences in sAA in relation to descriptive characteristics are shown in Table 2. For both men and women, mean sAA was higher in older and less educated persons. Mean sAA were also higher in both men and women who were unemployed, employed part-time, or self-employed compared with those who were employed full-time. Men who were more physically active had lower sAA. Women who were obese and had higher parasympathetic activity (i.e., lower SDNN or RMSSD) had higher mean sAA. Women who did not smoke and did not drink had higher mean sAA. All of these associations were attenuated after adjusting age; meanwhile, mean sAA remained higher in women who were unemployed or had part-time employment compared with those who were full-time employed (data not shown).

Some 783 participants had measures of both PD and sAA, and the mean sAA was 3.07(0.92) for men with chronic periodontitis and 2.91(0.89) for men without it $(p=0.15)$. The mean sAA was $3.46(0.85)$ for women with chronic periodontitis and $3.45(0.77)$ for women without it $(p=0.84)$.

Multivariate adjusted linear associations between sAA per 1-tandard deviation (SD) and the levels of glucose (fasting, 2-hr OGTT), insulin resistance (HOMA-IR), and systolic and diastolic blood pressures are shown in Table 3. There were significant positive associations between sAA and fasting glucose $(\beta=0.008 ; 95 \% \mathrm{CI}=0.002,0.014), 2-\mathrm{hr}$ postload glucose $(\beta=0.023 ; 95 \% \mathrm{CI}=0.004,0.041)$, HOMAIR $(\beta=0.032 ; 95 \% \mathrm{CI}=0.000,0.064)$ as well as systolic $(\beta=1.603 ; 95 \% \mathrm{CI}=0.479,2.726)$ and diastolic $(\beta=0.906 ; 95 \% \mathrm{CI}=0.212,1.600)$ blood pressures among women. These associations remained significant after further adjustment for HRV measures (i.e., SDNN, RMSSD, LF/HF ratio). In men, sAA was not significantly associated with any of the outcomes we measured.

We then checked for potential effect modification by stratifying the analyses by SDNN, RMSSD, and LF/HF ratio (Supplemental Table 1). We found there were interactions by SDNN and RMSSD for the association between SAA and SBP. The positive association between sAA and SBP was more evident in women who had higher levels of SDNN $(\beta=2.394$; $95 \% \mathrm{CI}=0.848,3.941)$ and $\mathrm{RMSSD}(\beta=2.300 ; 95 \%$ $\mathrm{CI}=0.792,3.809)$ compared to those with lower levels of SDNN $(\beta=0.987 ; 95 \% \mathrm{CI}=-0.676,2.649 ; P$ for interaction: $p=0.005)$ and RMSSD $(\beta=0.916$; 95\% CI $=-0.750,2.583 ; P$ for interaction: $p=0.03)$. There were no statistically significant interactions related to the $\mathrm{LF} / \mathrm{HF}$ ratio for any of the outcomes studied.

\section{Discussion}

In this cross-sectional analysis in a Japanese population, we found a significant association between sAA and the level of glucose, insulin resistance, and blood pressure among Japanese women. We found evidence of effect modification by SDNN and RMSSD, with a stronger association between sAA and SBP among women with higher levels of SDNN or RMSSD, but there were no interactions for metabolic 
Table 1. Demographic, behavioral, and biomedical factors separated by participant sex

\begin{tabular}{|c|c|c|c|}
\hline & $\begin{array}{c}\text { Men } \\
(n=473)\end{array}$ & $\begin{array}{c}\text { Women } \\
(n=1,029)\end{array}$ & $\begin{array}{c}P \text {-for } \\
\text { difference }\end{array}$ \\
\hline \multicolumn{4}{|l|}{ Age, y } \\
\hline $30-49, n(\%)$ & $91(19.2)$ & $229(22.3)$ & 0.002 \\
\hline $50-59, n(\%)$ & $66(14.0)$ & $210(20.4)$ & \\
\hline $60-69, n(\%)$ & $168(35.5)$ & $341(33.1)$ & \\
\hline$\geq 70, n(\%)$ & $148(31.3)$ & $249(24.2)$ & \\
\hline \multicolumn{4}{|l|}{ Education attainment level } \\
\hline$<$ college education, $n(\%)$ & $281(59.4)$ & $876(85.1)$ & $<0.001$ \\
\hline$\geq$ college education, $n(\%)$ & $192(40.6)$ & $153(14.9)$ & \\
\hline \multicolumn{4}{|l|}{ Marital status } \\
\hline Non-married, $n(\%)$ & $45(9.5)$ & $220(21.4)$ & $<0.001$ \\
\hline Married, $n(\%)$ & $428(90.5)$ & $806(78.6)$ & \\
\hline \multicolumn{4}{|l|}{ Employment Status } \\
\hline Unemployed, $n(\%)$ & $176(37.5)$ & $545(53.5)$ & $<0.001$ \\
\hline Full-time, $n(\%)$ & $118(25.2)$ & $82(8.1)$ & \\
\hline Part-time, $n(\%)$ & $52(11.1)$ & $303(29.8)$ & \\
\hline Self-employed, $n(\%)$ & $123(26.2)$ & $88(8.6)$ & \\
\hline \multicolumn{4}{|l|}{ Depression } \\
\hline No, $n(\%)$ & $427(90.5)$ & $927(90.5)$ & 0.97 \\
\hline Yes, $n(\%)$ & $45(9.5)$ & $97(9.5)$ & \\
\hline \multicolumn{4}{|l|}{ Smoking status } \\
\hline Non-smoker, $n(\%)$ & $405(85.6)$ & $1006(97.8)$ & $<0.001$ \\
\hline Current smoker, $n(\%)$ & $68(14.4)$ & $23(2.2)$ & \\
\hline \multicolumn{4}{|l|}{ Alcohol intake } \\
\hline Non-drinker, $n(\%)$ & $113(23.9)$ & $609(59.2)$ & $<0.001$ \\
\hline Current drinker, $n(\%)$ & $360(76.1)$ & $420(40.8)$ & \\
\hline \multicolumn{4}{|l|}{ Physical Activity (Women), Mets } \\
\hline$<24.2 \quad(<26.2), n(\%)$ & $117(24.7)$ & $256(24.8)$ & 0.99 \\
\hline $24.2-26.8 \quad(26.2-28.4), n(\%)$ & $118(24.9)$ & $258(25.1)$ & \\
\hline 26.9-30.1 (28.4-30.8), $n(\%)$ & $119(25.2)$ & $257(25.0)$ & \\
\hline$>30.1 \quad(>30.8), n(\%)$ & $119(25.2)$ & $258(25.1)$ & \\
\hline \multicolumn{4}{|l|}{ Menopause } \\
\hline No, $n(\%)$ & & $259(25.2)$ & \\
\hline Yes, $n(\%)$ & & $770(74.8)$ & \\
\hline \multicolumn{4}{|l|}{ Obesity } \\
\hline $\mathrm{BMI}<25$ & $331(70.0)$ & $826(80.3)$ & $<0.001$ \\
\hline $\mathrm{BMI} \geq 25$ & $142(30.0)$ & $203(19.7)$ & \\
\hline \multicolumn{4}{|c|}{ Chronic periodontitis (Probing depth $\geq 4 \mathrm{~mm}$ ) ${ }^{* *}$} \\
\hline No, $n(\%)$ & $123(50.4)$ & $335(62.2)$ & 0.002 \\
\hline Yes, $n(\%)$ & $121(49.6)$ & $204(37.8)$ & \\
\hline \multicolumn{4}{|l|}{ SDNN*, quartiles in men (in women) } \\
\hline$<3.33 \quad(<3.25), n(\%)$ & $116(24.6)$ & $251(24.4)$ & 0.99 \\
\hline $3.33-3.62 \quad(3.25-3.54), n(\%)$ & $120(25.4)$ & $264(25.7)$ & \\
\hline $3.63-3.93 \quad(3.55-3.84), n(\%)$ & $117(24.8)$ & $255(24.8)$ & \\
\hline$>3.93 \quad(>3.84), n(\%)$ & $119(25.2)$ & $259(25.1)$ & \\
\hline
\end{tabular}


(Cont. Table 1)

\begin{tabular}{|c|c|c|c|}
\hline & $\begin{array}{c}\text { Men } \\
(n=473)\end{array}$ & $\begin{array}{c}\text { Women } \\
(n=1,029)\end{array}$ & $\begin{array}{c}P \text {-for } \\
\text { difference }\end{array}$ \\
\hline \multicolumn{4}{|l|}{ RMSSD*, quartiles in men (in women) } \\
\hline$<2.83 \quad(<2.83), n(\%)$ & $122(25.9)$ & $248(24.1)$ & 0.02 \\
\hline $2.83-3.14 \quad(2.83-3.22), n(\%)$ & $92(19.4)$ & $264(25.7)$ & \\
\hline $3.15-3.64 \quad(3.23-3.58), n(\%)$ & $136(28.8)$ & $239(23.2)$ & \\
\hline$>3.64 \quad(>3.58), n(\%)$ & $122(25.9)$ & $278(27.0)$ & \\
\hline \multicolumn{4}{|l|}{ LF/HF Ratio*, quartiles in men (in women) } \\
\hline$<1.00 \quad(<0.93), n(\%)$ & $122(25.9)$ & $248(24.1)$ & 0.76 \\
\hline $1.00-1.12 \quad(0.93-1.04), n(\%)$ & $114(24.1)$ & $272(26.4)$ & \\
\hline $1.13-1.30 \quad(1.05-1.18), n(\%)$ & $117(24.8)$ & $258(25.1)$ & \\
\hline$>1.30 \quad(>1.18), n(\%)$ & $119(25.2)$ & $251(24.4)$ & \\
\hline \multicolumn{4}{|l|}{ Heart Rate, quartiles in men (in women) } \\
\hline$<60.0 \quad(<64.0), n(\%)$ & $112(23.7)$ & $262(25.4)$ & 0.90 \\
\hline 60.0-65.0 (64.0-68.0), $n(\%)$ & $118(25.0)$ & $247(24.0)$ & \\
\hline 66.0-71.0 (69.0-74.0), $n(\%)$ & $122(25.9)$ & $260(25.3)$ & \\
\hline$>71.0 \quad(>74.0), n(\%)$ & $120(25.4)$ & $260(25.3)$ & \\
\hline Fasting glucose ${ }^{*} \mathrm{mmol} / \mathrm{L}$, mean $(\mathrm{SD})$ & $1.69(0.10)$ & $1.63(0.10)$ & $<0.001$ \\
\hline 2-hr postload glucose ${ }^{*} \mathrm{mmol} / \mathrm{L}$, mean (SD) & $1.98(0.31)$ & $1.93(0.30)$ & 0.005 \\
\hline HOMA-IR* ${ }^{*}$ mean $(S D)$ & $0.27(0.63)$ & $0.11(0.57)$ & $<0.001$ \\
\hline Systolic Blood Pressure mmHg, mean (SD) & $126.5(17.4)$ & $120.8(19.5)$ & $<0.001$ \\
\hline Diastolic Blood Pressure mmHg, mean (SD) & $79.3(10.1)$ & $72.7(11.2)$ & $<0.001$ \\
\hline Salivary $\alpha$-Amylase ${ }^{* * *} \mathrm{U} / \mathrm{mL}$, mean (SD) & $2.75(0.92)$ & $3.27(0.91)$ & $<0.001$ \\
\hline
\end{tabular}

*Natural log-transformed; ${ }^{* *}$ Used a sample of the study population $(n=783)$ in 2014-2015; ${ }^{* * *}$ Natural log-transformed and divided by total saliva volume

Table 2. Association of salivary $\alpha$-amylase * with demographic, behavioral, and biomedical factors

\begin{tabular}{|c|c|c|c|c|c|c|c|c|}
\hline & \multicolumn{4}{|c|}{ Men $(n=473)$} & \multicolumn{4}{|c|}{ Women $(n=1,029)$} \\
\hline \multicolumn{9}{|l|}{ Age, $y$} \\
\hline $30-49$ & 91 & 2.40 & 0.92 & $<0.001$ & 229 & 2.88 & 0.90 & $<0.001$ \\
\hline $50-59$ & 66 & 2.43 & 0.84 & & 210 & 3.12 & 0.83 & \\
\hline$\geq 70$ & 148 & 3.09 & 0.88 & & 249 & 3.63 & 0.94 & \\
\hline \multicolumn{9}{|c|}{ Education attainment level } \\
\hline$<$ college education & 281 & 2.85 & 0.93 & 0.006 & 876 & 3.31 & 0.90 & 0.001 \\
\hline$\geq$ college education & 192 & 2.61 & 0.88 & & 153 & 3.05 & 0.92 & \\
\hline \multicolumn{9}{|l|}{ Marital status } \\
\hline \multicolumn{9}{|l|}{ Employment Status } \\
\hline Unemployed & 176 & 2.97 & 0.92 & $<0.001$ & 545 & 3.40 & 0.91 & $<0.001$ \\
\hline Full-time & 118 & 2.45 & 0.90 & & 82 & 2.84 & 0.85 & \\
\hline Part-time & 52 & 2.81 & 0.83 & & 303 & 3.14 & 0.90 & \\
\hline Self-employed & 123 & 2.72 & 0.89 & & 88 & 3.28 & 0.83 & \\
\hline
\end{tabular}


(Cont. Table 2)

\begin{tabular}{llrccccc}
\multicolumn{3}{c}{ Men $(n=473)$} & \multicolumn{3}{c}{ Women $(n=1,029)$} \\
\hline$n$ & Mean & SD & $\begin{array}{c}P \text {-for } \\
\text { difference }\end{array}$ & $n$ & Mean & SD & $\begin{array}{c}P \text {-for } \\
\text { difference }\end{array}$
\end{tabular}

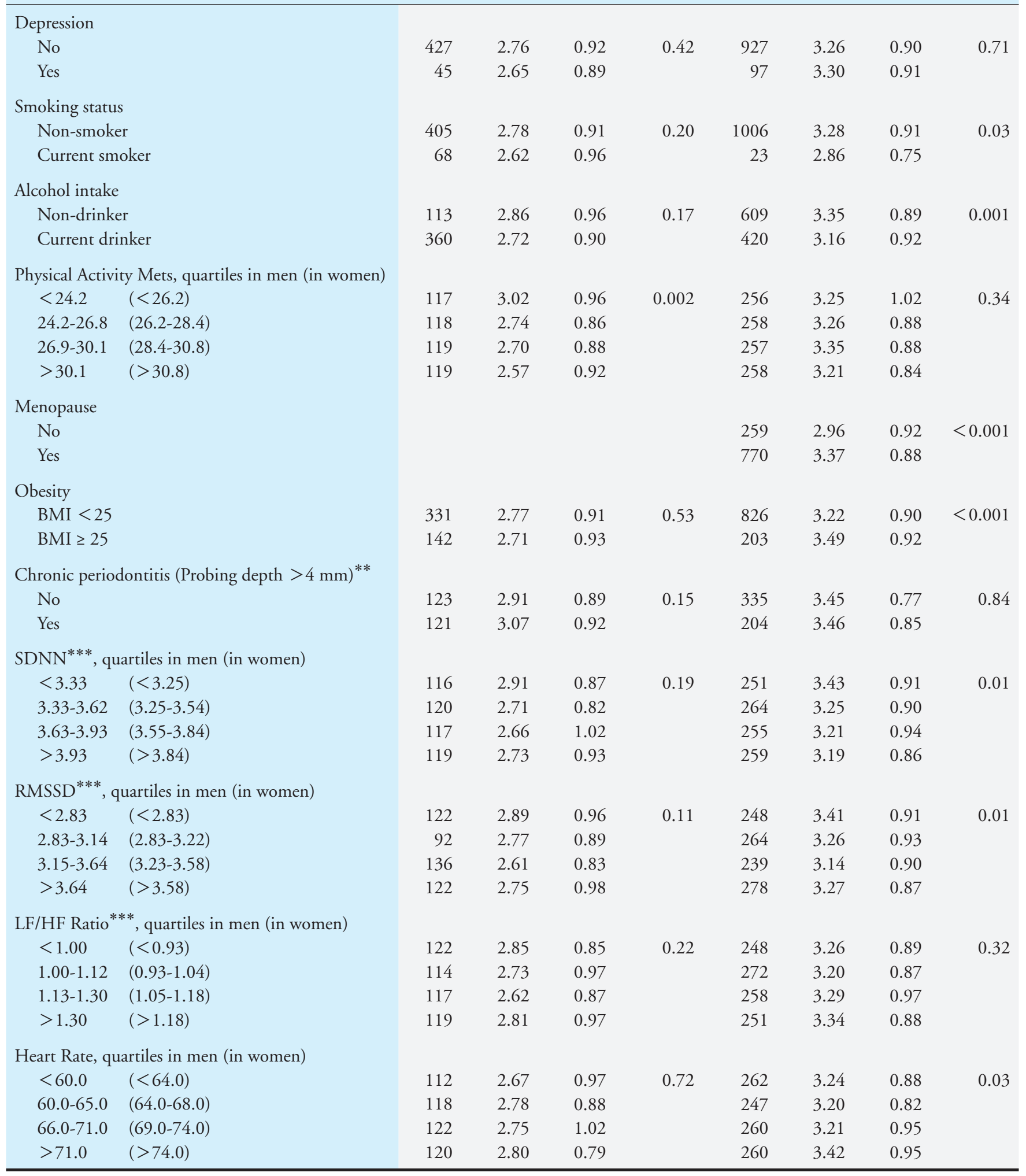

*Natural log-transformed and divided by total saliva volume; ${ }^{* *}$ Used a sample of the study population $(n=783)$ in $2014-2015 ;{ }^{* * *}$ Natural logtransformed. 
Table 3. Association of salivary $\alpha$-amylase with cardiometabolic status

\begin{tabular}{|c|c|c|c|c|c|c|c|c|}
\hline & \multicolumn{4}{|c|}{ Men $(n=473)$} & \multicolumn{4}{|c|}{ Women $(n=1,029)$} \\
\hline \multicolumn{9}{|l|}{ Fasting glucose, $\mathrm{mmol} / \mathrm{L}$} \\
\hline Multivariate model & 0.003 & $(-0.007,0.012)$ & 0.025 & 0.59 & 0.008 & $(0.002,0.014)$ & 0.080 & 0.008 \\
\hline Multivariate model ${ }^{*}$ & 0.003 & $(-0.007,0.013)$ & 0.028 & 0.56 & 0.008 & $(0.002,0.014)$ & 0.083 & 0.006 \\
\hline \multicolumn{9}{|c|}{ 2-hr postload glucose, $\mathrm{mmol} / \mathrm{L}$} \\
\hline Multivariate model & -0.006 & $(-0.033,0.022)$ & -0.018 & 0.69 & 0.023 & $(0.004,0.041)$ & 0.073 & 0.02 \\
\hline Multivariate model $^{*}$ & -0.005 & $(-0.033,0.023)$ & -0.016 & 0.71 & 0.023 & $(0.004,0.041)$ & 0.073 & 0.02 \\
\hline Multivariate model ${ }^{* *}$ & -0.005 & $(-0.033,0.022)$ & -0.017 & 0.71 & 0.023 & $(0.005,0.041)$ & 0.074 & 0.01 \\
\hline Multivariate model $^{*}$ & 0.024 & $(-0.024,0.072)$ & 0.037 & 0.33 & 0.032 & $(0.000,0.064)$ & 0.055 & 0.05 \\
\hline Multivariate model $^{* *}$ & 0.022 & $(-0.026,0.070)$ & 0.035 & 0.36 & 0.034 & $(0.002,0.065)$ & 0.057 & 0.04 \\
\hline Multivariate model ${ }^{* * *}$ & 0.023 & $(-0.025,0.072)$ & 0.037 & 0.34 & 0.032 & $(0.000,0.064)$ & 0.054 & 0.05 \\
\hline \multicolumn{9}{|l|}{ SBP, mmHg } \\
\hline Multivariate model & 0.291 & $(-1.295,1.877)$ & 0.016 & 0.72 & 1.603 & $(0.479,2.726)$ & 0.079 & 0.005 \\
\hline Multivariate model ${ }^{*}$ & 0.341 & $(-1.237,1.920)$ & 0.019 & 0.67 & 1.604 & $(0.480,2.728)$ & 0.079 & 0.005 \\
\hline Multivariate model ${ }^{* *}$ & 0.315 & $(-1.258,1.888)$ & 0.018 & 0.69 & 1.626 & $(0.503,2.749)$ & 0.080 & 0.005 \\
\hline Multivariate model ${ }^{* * *}$ & 0.327 & $(-1.252,1.905)$ & 0.018 & 0.68 & 1.573 & $(0.451,2.696)$ & 0.078 & 0.006 \\
\hline \multicolumn{9}{|l|}{ DBP, mmHg } \\
\hline
\end{tabular}

Salivary $\alpha$-amylase was natural log-transformed and divided by total saliva volume; Difference in outcomes is based on each 1-SD increase in $\alpha$ -amylase value; Glucose and HOMA-IR were natural log-transformed; Adjusted for age (years), BMI (kg/m²), physical activity (METs, quartiles), menopause (yes or no), employment status (full-time, part-time or self-employed), college education (yes or no), smoking status (current smoker or not), drinking status (current drinker or not) and hypertension medication use. ${ }^{*}$ Further adjusted for SDNN; ${ }^{* *}$ Further adjusted for RMSSD; ${ }^{* * *}$ Further adjusted for the LF/HF ratio.

outcomes. However, the effect modification by SDNN and RMSSD could be a chance finding given the multiple testing: this finding needs to be replicated in another sample. Among Japanese men, we found no significant association between sAA and any of outcomes we studied.

Our study suggests that sAA is associated with an increase in the level of fasting glucose, insulin resistance, and blood pressure in women. sAA has often been used as a marker of $\beta$-adrenergic activity during stress ${ }^{26)}$ given that the secretion of sAA is predominantly stimulated by $\beta$-adrenergic receptors ( $\beta$ -ARs $)^{27)}$. The pathological conditions characterized by excessive activation of sympathetic nervous system and sustained stimulation of $\beta$-ARs due to stress were associated with the development of hypertension and insulin resistance, and alteration of glucose homeosta$\operatorname{sis}^{28,29)}$. The present study further showed that these associations remained statistically significant even after adjustment for HRV measures. We also found that the association between sAA and SBP was more evident in women with normal sympathetic activity as defined by a higher level of SDNN or RMSSD (Supplemental Table 1). Taken together, the elevation of sAA may reflect a dysfunction of the sympathetic nervous system-associated with cardiometabolic abnormalities, such that the expected association between sAA and SBP breaks down among people with greater sympathetic drive.

The associations between sAA and cardiometabolic dysregulation differ by gender in the present study. Previous studies have reported that women tend 
to experience higher state anxiety and more negative mood than men ${ }^{30,31)}$. Studies of subjective emotion experience have found that women reported greater sadness $^{32,33)}$ and anxiety/fear ${ }^{33,34)}$ than men. Moreover, previous laboratory studies have suggested that there are gender differences in the relationships between stress and behavioral arousal ${ }^{35)}$ as well as some markers of cardiovascular arousal ${ }^{36-39)}$. Moreover, a large cohort study of Japanese men $(n=30,180)$ and women $(n=43,244)$ found that women with high perceived stress had an excess risk of cardiovascular mortality compared to those with low perceived stress, but a similar association was not found in $\mathrm{men}^{40)}$. These gender differences in response to stress may influence the effect of sAA on cardiometabolic dysregulation in the present study. However, there were fewer men compared with women in present study. Thus, further research is needed to confirm the gender difference in associations between sAA and metabolic abnormalities.

We found that individuals who were unemployed or had part-time employment had higher mean of sAA compared with full-time employed persons in the current study. A cross-sectional study with a national representative sample of employees in Japan found poorer mental health among people working as temporary contract workers ${ }^{41)}$. Lower socioeconomic status (i.e., low household income level, low education level) populations appear to experience more psychological distress ${ }^{42)}$ probably through exposure to chronic stressors related to social and environmental conditions including residential settings, poverty, underemployment, and economic constraints ${ }^{43}$. For women, earlier studies of stress and cardiovascular disease have emphasized the need to examine the effects of stress from multiple social roles such as marriage, motherhood, and caregiving for adult relatives, as well as the combinations of multiple roles ${ }^{44)}$. However, we were not able to consider all of these social roles in the present study. Our findings add to the literature on the potential of social stress processes to underly the association between stress and development of cardiovascular disease; however, a limited set of mechanisms through which sAA may be associated with cardiometabolic dysfunction were available for investigation in the current study, and the direction of causality cannot be fully determined.

Nater et al. (2006) reported that experimental social stress, consisting of a mental arithmetic task and free speech in front of an audience, stimulated elevated sAA; they also found that alpha-amylase responses were not closely related to responses in catecholamines and cortisol in the stress condition ${ }^{11)}$. Our findings suggest that sAA may be a useful measure of psychobiological stress responses related to cardiometabolic dysfunction in population studies as well.

The regression coefficients relating sAA to the measures of glucose metabolism are relatively small. In the present study, each 1-SD increase in sAA was associated with a $0.08 \mathrm{mmol} / \mathrm{L}$ increase in fasting glucose and a $0.07 \mathrm{mmol} / \mathrm{L}$ increase in 2 -hr postload glucose. Similarly, a previous study has also documented significant, but small standardized regression coefficients of fasting glucose $(\beta=0.09, p<0.01)$ and of post OGTT glucose $(\beta=0.07, p<0.05)$ on chronic psychological stress ${ }^{45)}$. This confirms that psychological stress and its biological correlates are not the primary determinants of impaired glucose metabolism.

An increase in the concentration of sAA may occur along with a decrease in flow rate due to periodontitis ${ }^{46)}$. sAA was therefore divided by total saliva volume in our present analysis. Presence of chronic periodontitis was not associated with sAA in the subsample of the study population in which this was tested. We therefore conclude that the association between sAA and cardiometabolic status was not confounded by periodontal disease in the present study.

There was no association between $\mathrm{LF} / \mathrm{HF}$ ratio and sAA in this study. While the $\mathrm{LF} / \mathrm{HF}$ ratio is sometimes regarded as a measure of sympathetic drive, many authorities consider that it reflects the balance of sympathetic and parasympathetic activity ${ }^{47}$. However, this view has been challenged ${ }^{48)}$, and interpretation of measures taken over the short time period used in this study and 24-hr recordings may differ ${ }^{49)}$. Consequently, the lack of association with sAA is difficult to interpret in terms of autonomic activity.

This study was carried out in a large, well characterized sample of men and women. The THS collected data on amylase concentrations, HRV measures, fasting glucose, and insulin levels by OGTT as well as a large number of lifestyle variables. However, a major limitation of this study is the cross-sectional design, which limits our ability to draw causal inferences. Additionally, both sAA and HRV were assessed on a single occasion; therefore, we could not examine a dynamic relationship between sympathetic and parasympathetic nervous systems. Moreover, although we adjusted for various possible confounding factors in the current study, there is a possibility of residual confounding by unmeasured variables, such as genetic factors $^{50,51)}$, which may influence the cardiometabolic disease causality cascade. In the present study, the association between depressive symptoms and sAA was not significant. However, this null association may be due to the limited data on depressive symptoms, and further investigations of the associations using a wellestablished measure of depression such as the Centre 
for Epidemiologic Studies Depression Scale ${ }^{52)}$ are needed.

\section{Conclusion}

We found a significant association between sAA and the level of glucose, insulin resistance, and blood pressure among Japanese women. Ours is the first investigation of sAA and cardiometabolic dysregulation reported in an Asian population, which has lower levels of obesity than in western countries. These findings lend weight to the notion that the pattern of association between sAA and cardiovascular health outcomes is gender-specific. The relationships between sAA and fasting glucose, insulin resistance, and blood pressures were maintained after adjusting for a standard set of biological and behavioral factors, suggesting that other mechanisms should be considered.

\section{Acknowledgements}

The authors thank all staff members in the Toon Health Study for their painstaking efforts to conduct the baseline survey and follow-up.

\section{Funding}

This study was supported by JSPS KAKENHI Grant Numbers; JP16K09072, JP17KK0175, JP18H03056, JP18K10087, JP17K00881.

\section{Conflict of Interests}

All authors reported no conflict of interest disclosures.

\section{Ethical Approval}

This study was approved by the ethics committees of Juntendo University (Reference number:2014003) and Ehime University (Reference number:20-2).

\section{Contributorship}

AI, AS, and EB had the original idea and developed the study design. TT, IS, KM, NM, TK, SN and KT recruited study subjects and collected data. AI performed the statistical analyses. AI wrote the first draft of the manuscript and all authors contributed to the critical revision of the manuscript. All authors read and approved the final manuscript.

\section{References}

1) Danaei G, Finucane MM, Lu Y, Singh GM, Cowan MJ, Paciorek CJ, Lin JK, Farzadfar F, Khang YH, Stevens GA, Rao M, Ali MK, Riley LM, Robinson CA, and Ezzati M: National, regional, and global trends in fasting plasma glucose and diabetes prevalence since 1980: systematic analysis of health examination surveys and epidemiological studies with 370 country-years and $2 \cdot 7$ million participants. Lancet, 2011; 378: 31-40

2) Saito I: Epidemiological evidence of type 2 diabetes mellitus, metabolic syndrome, and cardiovascular disease in Japan. Circ J, 2012; 7: 1066-1073

3) Surwit RS, Schneider MS, and Feinglos MN: Stress and diabetes mellitus. Diabetes Care, 1992; 15: 1413-1422

4) Hackett RA, and Steptoe A: Type 2 diabetes mellitus and psychological stress - a modifiable risk factor. Nat Rev Endocrinol, 2017; 13: 547-560

5) Heraclides A, Chandola T, Witte DR, and Brunner EJ: Psychosocial stress at work doubles the risk of type 2 diabetes in middle-aged women: evidence from the Whitehall II study. Diabetes Care, 2009; 32: 2230-2235

6) Mommersteeg PM, Herr R, Zijlstra WP, Schneider S, and Pouwer F: Higher levels of psychological distress are associated with a higher risk of incident diabetes during 18 year follow-up: results from the British household panel survey. BMC Public Health, 2012; 12: 1109

7) Eriksson AK, van den Donk M, Hilding A, and Östenson CG: Work stress, sense of coherence, and risk of type 2 diabetes in a prospective study of middle-aged Swedish men and women. Diabetes Care, 2013; 36: 2683-2689

8) Novak M, Björck L, Giang KW, Heden-Ståhl C, Wilhelmsen L, and Rosengren A: Perceived stress and incidence of Type 2 diabetes: a 35-year follow-up study of middle-aged Swedish men. Diabet Med, 2013; 30: e8-16

9) Siddiqui A, Madhu SV, Sharma SB, and Desai NG: Endocrine stress responses and risk of type 2 diabetes mellitus. Stress, 2015; 18: 498-506

10) Speirs RL, Herring J, Cooper WD, Hardy CC, and Hind CR: The influence of sympathetic activity and isoprenaline on the secretion of amylase from the human parotid gland. Arch Oral Biol, 1974; 19: 747-752

11) Nater UM, La Marca R, Florin L, Moses A, Langhans W, Koller MM, and Ehlert U: Stress-induced changes in human salivary alpha-amylase activity -- associations with adrenergic activity. Psychoneuroendocrinology, 2006; 31: 49-58

12) Nater UM, and Rohleder N: Salivary alpha-amylase as a non-invasive biomarker for the sympathetic nervous system: current state of research. Psychoneuroendocrinology, 2009; 34: 486-496

13) Bosch JA, Brand HS, Ligtenberg TJ, Bermond B, Hoogstraten J, and Nieuw Amerongen AV: Psychological stress as a determinant of protein levels and salivary-induced aggregation of Streptococcus gordonii in human whole saliva. Psychosom Med, 1996; 58: 374-382

14) Bosch JA, de Geus EJ, Veerman EC, Hoogstraten J, and Nieuw Amerongen AV: Innate secretory immunity in response to laboratory stressors that evoke distinct patterns of cardiac autonomic activity. Psychosom Med, 2003; 65: 245-258 
15) Kang Y: Psychological Stress-Induced Changes in Salivary Alpha-Amylase and Adrenergic Activity. Nurs Health Sci, 2010; 12: 477-484

16) Schroeder EB, Chambless LE, Liao D, Prineas RJ, Evans GW, Rosamond WD, and Heiss G: Diabetes, glucose, insulin, and heart rate variability: The Atherosclerosis Risk in Communities (ARIC) study. Diabetes Care, 2005; 28: 668-674

17) Chang CJ, Yang YC, Lu FH, Lin TS, Chen JJ, Yeh TL, Wu CH, and Wu JS: Altered cardiac autonomic function may precede insulin resistance in metabolic syndrome. Am J Med, 2010; 123: 432-438

18) Singh JP, Larson MG, Tsuji H, Evans JC, O’Donnell CJ, and Levy D: Reduced heart rate variability and new-onset hypertension: insights into pathogenesis of hypertension: the Framingham Heart Study. Hypertension, 1998; 32: 293-297

19) Saito I, Maruyama K, Eguchi E, Kato T, Kawamura R, Takata Y, Onuma H, Osawa H, and Tanigawa T: Low Heart Rate Variability and Sympathetic Dominance Modifies the Association Between Insulin Resistance and Metabolic Syndrome-The Toon Health Study. Circ J, 2017; 81: $1447-1453$

20) Higuchi K, Saito I, Maruyama K, Eguchi E, Mori H, Tanno S, Sakurai S, Kishida T, Nishida W, Osawa H, and Tanigawa T: Associations of serum $\beta$-carotene and retinol concentrations with insulin resistance: the Toon Health Study. Nutrition, 2015; 31: 975-980

21) Saito I, Takata Y, Maruyama K, Eguchi E, Kato T, Shirahama R, Tomooka K, Kawamura R, Sano M, Tabara Y, Osawa $\mathrm{H}$, and Tanigawa T: Association Between Heart Rate Variability and Home Blood Pressure: The Toon Health Study. Am J Hypertens, 2018; 31: 1120-1126

22) Matthews DR, Hosker JP, Rudenski AS, Naylor BA, Treacher DF, and Turner RC: Homeostasis model assessment: insulin resistance and beta-cell function from fasting plasma glucose and insulin concentrations in man. Diabetologia, 1985; 28: 412-419

23) Ishikawa-Takata $K$, Naito $Y$, Tanaka $S$, Ebine $N$, and Tabata I: Use of doubly labeled water to validate a physical activity questionnaire developed for the Japanese population. J Epidemiol, 2011; 21: 114-121

24) Ainsworth BE, Haskell WL, Whitt MC, Irwin ML, Swartz AM, Strath SJ, O'Brien WL, Bassett DR Jr, Schmitz KH, Emplaincourt PO, Jacobs DR Jr, and Leon AS: Compendium of physical activities: an update of activity codes and MET intensities. Med Sci Sports Exerc, 2000; 32: S498-504

25) Miyoshi N, Tanigawa T, Nishioka S, Maruyama K, Eguchi E, Tanaka K, Saito I, Yamazaki K, and Miyake Y: Association of salivary lactate dehydrogenase level with systemic inflammation in a Japanese population. J Periodontal Res, 2018; 53: 487-494

26) van Stegeren A, Rohleder N, Everaerd W, and Wolf OT: Salivary alpha amylase as marker for adrenergic activity during stress: effect of betablockade. Psychoneuroendocrinology, 2006; 31: 137-141

27) Skov Olsen P, Kirkegaard P, Rasmussen T, Magid E, Poulsen SS, and Nexø E: Adrenergic effects on secretion of amylase from the rat salivary glands. Digestion, 1988; 41: $34-38$
28) Manolis AJ, Poulimenos LE, Kallistratos MS, Gavras I, and Gavras H: Sympathetic overactivity in hypertension and cardiovascular disease. Curr Vasc Pharmacol, 2014; 12: 4-15

29) Mangmool S, Denkaew T, Phosri S, Pinthong D, Parichatikanond W, Shimauchi T, and Nishida M: Sustained $\beta$ AR Stimulation Mediates Cardiac Insulin Resistance in a PKA-Dependent Manner. Mol Endocrinol, 2016; 30: 118-132

30) Kelly MM, Tyrka AR, Anderson GM, Price LH, and Carpenter LL: Sex differences in emotional and physiological responses to the Trier Social Stress Test. J Behav Ther Exp Psychiatry, 2008; 39: 87-98

31) Tomova L, von Dawans B, Heinrichs M, Silani G, and Lamm C: Is stress affecting our ability to tune into others? Evidence for gender differences in the effects of stress on self-other distinction. Psychoneuroendocrinology, 2014; 43: 95-104

32) Brebner J: Gender and emotions. Pers Individ Dif, 2003; 34: 387-394

33) Fischer AH, Mosquera PMR, van Vianen AEM, and Manstead ASR: Gender and culture differences in emotion. Emotion, 2004; 4: 87-94

34) Feingold A: Gender differences in personality: a metaanalysis. Psychol Bull, 1994; 116: 429-456

35) Zellner DA, Loaiza S, Gonzalez Z, Pita J, Morales J, Pecora $\mathrm{D}$, and Wolf A: Food selection changes under stress. Physiol Behav, 2006; 87: 789-793

36) Stone SV, Dembroski TM, Costa PT Jr, and MacDougall JM: Gender differences in cardiovascular reactivity. J Behav Med, 1990; 13: 137-156

37) Girdler SS, Turner JR, Sherwood A, and Light KC: Gender differences in blood pressure control during a variety of behavioral stressors. Psychosom Med, 1990; 52: 571591

38) Hurwitz BE, Nelesen RA, Saab PG, Nagel JH, Spitzer SB, Gellman MD, McCabe PM, Phillips DJ, and Schneiderman N: Differential patterns of dynamic cardiovascular regulation as a function of task. Biol Psychol, 1993; 36: 75-95

39) Rannelli LA, MacRae JM, Mann MC, Ramesh S, Hemmelgarn BR, Rabi D, Sola DY, and Ahmed SB: Sex differences in associations between insulin resistance, heart rate variability, and arterial stiffness in healthy women and men: a physiology study. Can J Physiol Pharmacol, 2017; 95: 349-355

40) Iso H, Date C, Yamamoto A, Toyoshima H, Tanabe N, Kikuchi S, Kondo T, Watanabe Y, Wada Y, Ishibashi T, Suzuki H, Koizumi A, Inaba Y, Tamakoshi A, and Ohno Y: Perceived mental stress and mortality from cardiovascular disease among Japanese men and women: the Japan Collaborative Cohort Study for Evaluation of Cancer Risk Sponsored by Monbusho (JACC Study). Circulation, 2002; 106: 1229-1236

41) Inoue $A$, Kawakami N, Tsuchiya M, Sakurai K, and Hashimoto H: Association of occupation, employment contract, and company size with mental health in a national representative sample of employees in Japan. J Occup Health, 2010; 52: 227-240

42) Honjo K, Kawakami N, Tsuchiya M, and Sakurai K: Association of subjective and objective socioeconomic sta- 
tus with subjective mental health and mental disorders among Japanese men and women. Int J Behav Med, 2014; 21: 421-429

43) Baum A, Garofalo JP, and Yali AM: Socioeconomic status and chronic stress. Does stress account for SES effects on health? Ann N Y Acad Sci, 1999; 896: 131-144

44) Low CA, Thurston RC, and Matthews KA: Psychosocial factors in the development of heart disease in women: current research and future directions. Psychosom Med, 2010; 72: 842-854

45) McCurley JL, Mills PJ, Roesch SC, Carnethon M, Giacinto RE, Isasi CR, Teng Y, Sotres-Alvarez D, Llabre MM, Penedo FJ, Schneiderman N, and Gallo LC: Chronic stress, inflammation, and glucose regulation in U.S. Hispanics from the HCHS/SOL Sociocultural Ancillary Study. Psychophysiology, 2015; 52: 1071-1079

46) Sánchez GA, Miozza V, Delgado A, Busch L: Determination of salivary levels of mucin and amylase in chronic periodontitis patients. J Periodontal Res. 2011; 46: 221227

47) Pagani M, Lombardi F, Guzzetti S, Rimoldi O, Furlan R, Pizzinelli P, Sandrone G, Malfatto G, Dell'Orto S, Pic- caluga E: Power spectral analysis of heart rate and arterial pressure variabilities as a marker of sympatho-vagal interaction in man and conscious dog. Circulation Research, 1986; 59: 178-193

48) Billman GE: The LF/HF Ratio Does Not Accurately Measure Cardiac Sympatho-Vagal Balance. Front Physiol, 2013; 4: 26

49) Shaffer F, Ginsberg JP: An Overview of Heart Rate Variability Metrics and Norms. Front. Public Health, 2017; 5: $1-17$

50) Mandel AL and Breslin PA: High endogenous salivary amylase activity is associated with improved glycemic homeostasis following starch ingestion in adults. J Nutr, 2012; 142: 853-858

51) Marquina C, Mousa A, Belski R, Banaharis $H$, Naderpoor $\mathrm{N}$, and de Courten B: Increased Inflammation and Cardiometabolic Risk in Individuals with Low AMY1 Copy Numbers. J Clin Med, 2019; 8

52) Radloff LS: The CES-D scale: a self-report depression scale for research in general population. Appl Psychol Meas, 1977; 1: 385-401 
Supplemental Table 1. Associations between salivary $\alpha$-amylase and each of cardiometabolic risk markers stratified by SDNN, RMSSD, and the LF/HF ratio

\begin{tabular}{|c|c|c|c|c|c|c|c|c|c|}
\hline Men & & & & & & & & & \\
\hline & Coefficient & $95 \%$ CI & $\begin{array}{l}\text { Standardized } \\
\text { Coefficient }\end{array}$ & $P$-value & Coefficient & $95 \% \mathrm{CI}$ & $\begin{array}{c}\text { Standardized } \\
\text { Coefficient }\end{array}$ & $P$-value & $\begin{array}{c}P \text { for } \\
\text { Interaction }\end{array}$ \\
\hline & \multicolumn{4}{|c|}{ SDNN <3.63 $(n=236)$} & \multicolumn{4}{|c|}{$\mathrm{SDNN} \geq 3.63(n=236)$} & \\
\hline Fasting glucose, $\mathrm{mmol} / \mathrm{L}$ & -0.001 & $(-0.017,0.016)$ & -0.005 & 0.94 & 0.007 & $(-0.005,0.018)$ & 0.075 & 0.25 & 0.47 \\
\hline $2 \mathrm{hr}$-postload glucose, $\mathrm{mmol} / \mathrm{L}$ & -0.013 & $(-0.058,0.033)$ & -0.036 & 0.58 & 0.009 & $(-0.025,0.044)$ & 0.032 & 0.59 & 0.62 \\
\hline HOMA-IR & 0.015 & $(-0.059,0.089)$ & 0.022 & 0.69 & 0.040 & $(-0.026,0.105)$ & 0.066 & 0.23 & 0.11 \\
\hline SBP, mmHg & 0.463 & $(-1.986,2.911)$ & 0.024 & 0.71 & -0.042 & $(-2.169,2.085)$ & -0.003 & 0.97 & 0.62 \\
\hline \multirow[t]{2}{*}{ DBP, $\mathrm{mmHg}$} & 0.581 & $(-0.854,2.015)$ & 0.053 & 0.43 & -0.702 & $(-1.999,0.595)$ & -0.072 & 0.29 & 0.09 \\
\hline & \multicolumn{4}{|c|}{ RMSSD $<3.22(n=214)$} & \multicolumn{4}{|c|}{ RMSSD $\geq 3.55(n=258)$} & \\
\hline Fasting glucose, $\mathrm{mmol} / \mathrm{L}$ & -0.003 & $(-0.017,0.012)$ & -0.025 & 0.73 & 0.008 & $(-0.006,0.021)$ & 0.071 & 0.27 & 0.16 \\
\hline 2 hr-postload glucose, $\mathrm{mmol} / \mathrm{L}$ & -0.023 & $(-0.063,0.017)$ & -0.076 & 0.26 & 0.014 & $(-0.025,0.053)$ & 0.040 & 0.49 & 0.38 \\
\hline HOMA-IR & -0.024 & $(-0.089,0.040)$ & -0.044 & 0.46 & 0.059 & $(-0.013,0.131)$ & 0.085 & 0.11 & 0.03 \\
\hline SBP, mmHg & 0.654 & $(-1.637,2.945)$ & 0.038 & 0.57 & -0.338 & $(-2.588,1.911)$ & -0.019 & 0.77 & 0.94 \\
\hline \multirow[t]{2}{*}{ DBP, $\mathrm{mmHg}$} & 0.740 & $(-0.638,2.119)$ & 0.074 & 0.29 & -1.014 & $(-2.339,0.311)$ & -0.099 & 0.13 & 0.26 \\
\hline & \multicolumn{4}{|c|}{ LF/HF Ratio <1.14 $(n=236)$} & \multicolumn{4}{|c|}{ LF/HF Ratio $\geq 1.14(n=236)$} & \\
\hline Fasting glucose, $\mathrm{mmol} / \mathrm{L}$ & 0.004 & $(-0.010,0.017)$ & 0.037 & 0.59 & 0.003 & $(-0.012,0.017)$ & 0.025 & 0.71 & 0.48 \\
\hline $2 \mathrm{hr}$-postload glucose, $\mathrm{mmol} / \mathrm{L}$ & -0.025 & $(-0.064,0.015)$ & -0.080 & 0.22 & 0.008 & $(-0.032,0.049)$ & 0.025 & 0.69 & 0.58 \\
\hline HOMA-IR & 0.062 & $(-0.007,0.131)$ & 0.099 & 0.08 & -0.031 & $(-0.101,0.040)$ & -0.047 & 0.40 & 0.72 \\
\hline SBP, mmHg & 0.938 & $(-1.501,3.378)$ & 0.050 & 0.45 & -0.338 & $(-2.502,1.826)$ & -0.020 & 0.76 & 0.31 \\
\hline DBP, $\mathrm{mmHg}$ & 0.142 & $(-1.250,1.534)$ & 0.014 & 0.84 & -0.280 & $(-1.647,1.087)$ & -0.028 & 0.69 & 0.41 \\
\hline \multicolumn{10}{|l|}{ Women } \\
\hline & \multicolumn{4}{|c|}{$\mathrm{SDNN}<3.55(n=515)$} & \multicolumn{4}{|c|}{$\mathrm{SDNN} \geq 3.55(n=514)$} & \\
\hline Fasting glucose, $\mathrm{mmol} / \mathrm{L}$ & 0.007 & $(-0.002,0.016)$ & 0.071 & 0.11 & 0.009 & $(0.000,0.017)$ & 0.088 & 0.04 & 0.93 \\
\hline $2 \mathrm{hr}$-postload glucose, $\mathrm{mmol} / \mathrm{L}$ & 0.020 & $(-0.006,0.047)$ & 0.064 & 0.14 & 0.026 & $(0.000,0.053)$ & 0.088 & 0.05 & 0.65 \\
\hline HOMA-IR & 0.033 & $(-0.011,0.078)$ & 0.059 & 0.14 & 0.028 & $(-0.019,0.075)$ & 0.046 & 0.24 & 0.67 \\
\hline SBP, mmHg & 0.987 & $(-0.676,2.649)$ & 0.049 & 0.24 & 2.394 & $(0.848,3.941)$ & 0.119 & 0.003 & 0.005 \\
\hline \multirow[t]{2}{*}{ DBP, $\mathrm{mmHg}$} & 0.926 & $(-0.098,1.949)$ & 0.079 & 0.08 & 1.072 & $(0.116,2.028)$ & 0.094 & 0.03 & 0.29 \\
\hline & \multicolumn{4}{|c|}{ RMSSD $<3.26(n=512)$} & \multicolumn{4}{|c|}{ RMSSD $\geq 3.26(n=517)$} & \\
\hline Fasting glucose, $\mathrm{mmol} / \mathrm{L}$ & 0.009 & $(0.001,0.018)$ & 0.095 & 0.03 & 0.006 & $(-0.002,0.015)$ & 0.065 & 0.13 & 0.85 \\
\hline 2 hr-postload glucose, $\mathrm{mmol} / \mathrm{L}$ & 0.029 & $(0.004,0.055)$ & 0.097 & 0.03 & 0.014 & $(-0.013,0.040)$ & 0.044 & 0.31 & 0.50 \\
\hline HOMA-IR & 0.042 & $(0.000,0.084)$ & 0.076 & 0.05 & 0.014 & $(-0.035,0.062)$ & 0.022 & 0.59 & 0.85 \\
\hline SBP, mmHg & 0.916 & $(-0.750,2.583)$ & 0.045 & 0.28 & 2.300 & $(0.792,3.809)$ & 0.116 & 0.003 & 0.03 \\
\hline \multirow[t]{2}{*}{ DBP, mmHg } & 0.649 & $(-0.344,1.642)$ & 0.057 & 0.20 & 1.226 & $(0.256,2.197)$ & 0.105 & 0.01 & 0.22 \\
\hline & \multicolumn{4}{|c|}{ LF/HF Ratio < $1.04(n=520)$} & \multicolumn{4}{|c|}{ LF/HF Ratio $\geq 1.04(n=509)$} & \\
\hline Fasting glucose, $\mathrm{mmol} / \mathrm{L}$ & 0.002 & $(-0.006,0.010)$ & 0.021 & 0.63 & 0.011 & $(0.003,0.020)$ & 0.110 & 0.01 & 0.63 \\
\hline $2 \mathrm{hr}$-postload glucose, $\mathrm{mmol} / \mathrm{L}$ & 0.010 & $(-0.017,0.037)$ & 0.031 & 0.47 & 0.030 & $(0.005,0.055)$ & 0.102 & 0.02 & 0.63 \\
\hline HOMA-IR & 0.012 & $(-0.037,0.061)$ & 0.019 & 0.64 & 0.042 & $(0.000,0.085)$ & 0.076 & 0.05 & 0.90 \\
\hline SBP, mmHg & 1.893 & $(0.256,3.531)$ & 0.091 & 0.02 & 1.032 & $(-0.552,2.615)$ & 0.052 & 0.20 & 0.68 \\
\hline DBP, $\mathrm{mmHg}$ & 1.131 & $(0.111,2.151)$ & 0.095 & 0.03 & 0.688 & $(-0.279,1.656)$ & 0.061 & 0.16 & 0.64 \\
\hline
\end{tabular}

Salivary $\alpha$-amylase was natural log-transformed and divided by total saliva volume; Difference in outcomes is based on each 1-SD increase in $\alpha$ -amylase value; Glucose and HOMA-IR were natural log-transformed; Adjusted for age (years), BMI (kg/m²), physical activity (METs, quartiles), menopause (yes or no), employment status (full-time, part-time or self-employed), college education (yes or no), smoking status (current smoker or not), drinking status (current drinker or not) and hypertension medication use. 